Arteterapia. Papeles de arteterapia y educación para inclusión social ISSN-e 1988-8309

http://dx.doi.org/10.5209/ARTE.57565

\title{
Arquitecturas del pensamiento: el lugar de las palabras
}

\author{
María Victoria Martínez Vérez ${ }^{1}$; Javier Abad Molina²; Jose María Mesias Lema ${ }^{3}$
}

Recibido: 12 de enero de 2015 / Aceptado: 15 de febrero de 2015

Resumen. La expresión de las emociones colabora en la construcción de las diferentes identidades que conviven y se comparten en el ámbito educativo a través de la alteridad. Se propone la narración de la experiencia artística mediante la creación de un espacio-metáfora para ofrecer visibilidad al relato colectivo que describe los procesos de autoconstrucción del "yo" y del "nosotros" que reconoce esas emociones. Durante la acción performativa, los participantes aportan objetos simbólicos y ofrecen palabras significativas para representar hechos de su vida que dicen el lugar del otro. Esta propuesta interdisciplinar considera el contexto educativo como "arquitectura sensible" para el encuentro que permite construir identidades relacionales.

Palabras clave; Actividad artística; Aprendizaje social; Educación Comunitaria; Identidad; Narración.

\section{[en] The architectures of thought: the space of words.}

\begin{abstract}
The expression of emotions can help to build the different identities that coexist and are put in common in the educative environment by means of alterity. The study proposes the narration of the artistic experience by the creation of a "metaphor-space" to offer visibility to the collective story wich describes the auto-building of the "me" and the "US" and then recognizes those emotions. During the performing action, participants provide symbolic objects and share significative words to represent vital facts that "say other participant's place". This interdisciplinary proposal considers the educational context as a "sensitive architecture" to the meeting that allows building relational identities.
\end{abstract}

Key Words: Art Activity; Social Learning; Community education; Identity; Narration.

Sumario: 1. Introducción. 2. Habitar las emociones y la construcción del nosotros. 3. La palabra como tipificación para decir la vida y decir al otro. 4. La alteridad como encuentro: yo soy el otro. 5. Propuesta de acción: Arquitecturas del pensamiento. 6. Simbología de los lugares y los objetos para la acción. 7. Breve relato de la acción performativa. 8. Conclusiones. 9. Narrativas visuales de la acción performativa. 10. Referencias bibliográficas.

Es doctora en sociología por la Universidad de A Coruña, diplomada en trabajo social y licenciada en Sociología por las universidades de Santiago de Compostela y Pontificia de Salamanca.

Email: vita.martinez.verez@gmail.com

2 eEs doctor en Bellas Artes por la Universidad Complutense de Madrid, artista visual y profesor de Educación Artística del Centro Universitario La Salle (adscrito a la Universidad Autónoma de Madrid).

Email: j.abad@lasallecampus.es

3 Es doctor en Artes Visuales y Educación por la Universidad de Granada y profesor de Educación Artística en la Facultad de Ciencias de la Educación de A Coruña (UDC).

Jose.mesias@udc.es 
Cómo citar: Martínez Vérez, M.V.; Abad Molina, J.; Mesias Lema, J.M. (2017). Arquitecturas del pensamiento: el lugar de las palabras, México, en Arteterapia. Papeles de arteterapia y educación para inclusión social 12, 109-123.

\section{Introducción}

El "yo" y el "otro" son instancias recíprocas de autoconocimiento y construcción mutuas. El ser humano necesita de los otros para pertenecer y arraigarse a una identidad personal y colectiva (Elías, 1990b: 175), sin embargo, los procesos de alteridad se niegan en la escuela y a menudo en la vida, ya que forman parte de todo aquello que sucede fuera de lo concreto.

Así, las emociones están presentes en todos los procesos educativos, pese a no constar en ninguno. Son intangibles, impredecibles y sólo acontecen en lo inesperado. Existen sin verse, son subjetivas, lo impregnan todo y, sin embargo, no parecen existir en la "escuela oficial". Es cierto que las diferentes reformas han incorporado aspectos relacionados con la inteligencia emocional en los contenidos curriculares, pero sin alterar la estructura y organización académica. Intentar que los encuentros emocionales existan dentro de unas coordenadas precisas parece improbable, sin embargo, pretendemos que sea así.

En lo educativo parece existir un "discurso ilustrado" sobre el alumno y lo que se espera de él, su producción visible que, sin embargo, no tiene en cuenta su propia realidad y deseo pues debe encajar en todo lo programado. Así, la escuela, como agencia legitimadora de todo aquello que se ha de aprender, organiza y reglamenta los espacios y los procesos educativos de manera tal que sólo parece existir una única forma de proceder, la objetiva, olvidándose a menudo que es en los márgenes de los currículos donde aparece el asombro. Sin embargo, en la escuela y en la vida, lo inesperado no sólo debe suceder, sino que también ha de reconocerse, porque es de ahí donde parte el interés del alumno. En este sentido, las propuestas educativas han de procurar que la vida entre y salga del aula de la mano del educador, de los propios alumnos y del conjunto de la comunidad.

\section{Habitar las emociones y la construcción del nosotros.}

Cada persona lleva inscrita en su corporalidad emociones, crisis, certezas, dudas e instantes, que no se ven, pero que permanecen y que se representan en aspectos tangibles como la forma que tenemos de situarnos y de participar en el mundo social $\mathrm{y}$ en otros intangibles e incluso aparentemente banales, como el aroma personal que desprendemos, un orden o desorden concreto de las acciones que nos definen, la forma de escribir cada palabra, de leer, de nombrar o de emocionarnos, entre otras.

El cuerpo es un soporte personal y una realidad que surge ante el otro y que implica una respuesta inevitable. Cuando en mi horizonte aparece una persona, ésta, a su vez, se define a su vez como un espejo de mí mismo y como frontera precisa de mi propia realidad, y, en consecuencia, mi yo reacciona, adaptándose a los límites físicos o emocionales que esta corporalidad le impone y también propone. De este 
modo, la presencia de ese otro permite aprender que es en la "fricción" de las fronteras interpersonales dónde se producen los encuentros. Es decir, en ese lugar del símbolo o zona intermedia situada entre el yo interno y la realidad externa, se produce la experiencia cultural y emocional compartida que se encarnan en diferentes nosotros plenos de sentido.

Así, todos los agentes comunitarios (la familia, los iguales, los vecinos, los educadores, las instituciones), habitan e influyen en el mundo del alumno (niño o adolescente) en tanto que atienden sus necesidades, y entienden, o no, su propia diferencia. Pero no sólo eso, sino que el cuerpo del otro, en relación con el suyo propio, acerca a las personas los límites de un mundo donde lo virtual es tan real como lo empírico y es importante definir las fronteras del encuentro y los límites de la posibilidad. Decir las emociones, construidas con los otros, ayuda a lograrlo.

La comunidad, como institución, es el cuerpo social habitado en el que vivimos y como tal debe procurar que las personas se construyan en un mundo lleno de significado a través de la proximidad, es decir, en el cuerpo del otro, aunque ese cuerpo, ya no sea, sólo físico. En cualquier caso, los otros son parte del yo, y habitan la propia identidad, conformándola. No es posible "ser" aislado. Por eso, cada persona es encuentro, y, como tal, para nosotros es única, ya que sólo en el otro apreciamos nuestra diferencia y descubrimos la afinidad compartida a través del espacio-tiempo. Tanto es así que puede no existir una relación que separe el sujeto del objeto, ya que los seres humanos nos definimos, a la vez, como destino y destinado, camino y caminante, creación y creador. Las personas somos siempre en construcción, y vivimos sabiendo que la única certeza es el camino que nos recorre, por eso, responder ante "la otredad", es tan inevitable como vivir.

En cualquier caso, lo cierto, es que los seres humanos precisamos de la alteridad, aunque sólo sea para que otra persona nos sitúe en el mundo. En este sentido, Lévinas (1993) considera que la presencia del otro, nos desborda y limita nuestra jerarquía de infinito, ya que el cuerpo tangible existe, es absoluto y no se puede negar, de tal forma que incita a mi yo a responder, es decir, a caminar al encuentro de ese otro que me construye en relación. Y esta acción, de atención, rechazo o indiferencia, implica, de algún modo, emocionarnos, hacer lazo o deshacerlo, y asumir lo extraordinario. Arriesgarse a admitir al otro en nosotros mismos, albergando su presencia, interiorizando su propia diversidad como un valor constitutivo de la propia identidad, supone aceptar lo inesperado.

Por este motivo, Lévinas (1999), apuesta por crear una filosofía de la diferencia que parte de que lo importante no es la existencia en sí misma, sino la diferencia que determina cada existir y, en este sentido, resalta la relevancia del encuentro en la constitución del yo y del mundo que nos conforma, ya que es el otro quien nos sitúa en el plano afectivo y social, simplemente, al nombrarnos y al mirarnos. De modo similar, Bourdieu (2012: 96) considera que, "aunque existan instancias externas legitimadoras, únicamente a través de la mirada de los otros, las personas se definen en el mapa de la diferencia". Somos un único yo, que es nombrado, a su vez, como un otro en todas las personas que nos encuentran.

Por eso, las personas tienen la capacidad de transformar su entorno, a través de la palabra, la imagen, o el gesto, al distinguir unos espacios de los otros y unas personas de otras. Del mismo modo, las personas tenemos la capacidad de situar al otro en el mapa de la diferencia al otorgarle nuestra distinción. De este modo, pasamos de ocupar un espacio cualquiera, a tener un lugar en el otro. La diferencia entre ocupar 
un espacio y tener un lugar reside en la capacidad de acomodación de las personas ante la diversidad, ya que un espacio indica unas coordenadas geográficas, mientras que un lugar hace referencia a indicadores socio-afectivos. Así, mientras los espacios sólo están, los lugares son y se pueden decir, ya que suponen una experiencia distinta para cada persona; experiencia que, a su vez, le va a permitir crear diferentes "nosotros", en función de la adaptación que implica asumir al otro tal y como es, aceptándolo en su propia especificidad.

De algún modo, es la emoción la que marca la diferencia, la que define, establece y ordena las prioridades, tanto en lo que aprendemos curricularmente, como en la vida. Al final, recordamos aquello que nos conmueve, porque sólo lo que nos construye, permanece. Por eso, los procesos educativos socializadores deben vivenciarse, y reconstruirse constantemente, ya que "toda representación del individuo es necesariamente una representación del vínculo social que le es consustancial" (Augé, 2000: 26). Por eso, los procesos educativos han de tener en cuenta que las emociones, las magnitudes personales, temporales y espaciales, son relativas y propias al individuo y al entorno en que se realiza. De tal modo que, al aceptar la posibilidad y el asombro de la vida en relación, las personas se convierten en permanentes "buscadores" de sentido y de significado. Búsqueda que detalla Elías (1990a: 17) señalando que la desaparición de los límites tradicionales del conocimiento supuso la aparición de nuevas formas de pensamiento y percepción que exigen "la capacidad del ser humano de ver las cosas desde fuera y, al mismo tiempo, percibir aquello que se llama mío o nuestro como sistema parcial, incluido dentro de un sistema más amplio". Dicha dualidad ha de contemplarse en la educación formal.

Por tanto, la educación es, en definitiva, una acción de empoderamiento mutuo y es precisamente este encuentro emocional al que nos referimos cuando hablamos de la vida en relación. Pero, además, la comunidad, debe gestarse no sólo en los centros, en lo oficial, en lo previsible y en lo concreto, sino también en las fronteras, personales, temporales, espaciales y sociales. Este empoderamiento educativo debería permitir analizar críticamente las dinámicas de construcción social del "yo" y los "otros". Esto es, la búsqueda para reconocer el encuentro a través de las nuevas formas de manifestación de la experiencia estética contemporánea como deconstrucción de representaciones y discursos hegemónicos globales, dando paso a esas "otras" voces minoritarias que también están presentes y a veces son silenciadas.

\section{La palabra como tipificación para decir la vida y al otro.}

A través del lenguaje decimos la realidad que nos construye y explicamos todo aquello que necesita ser entendido. De esta manera, las personas ordenamos y ponemos en común nuestro sistema de realidad a través de las palabras como límite del mundo que compartimos y como generadoras de orden y sentido en las coordenadas propias del ser y estar, individual y colectivo. De acuerdo con todo ello, el lenguaje participa de este sistema de vida y organización social en tanto crea y recrea la comunidad al decir el mundo del que formamos parte inherente. De hecho, cada vez que hablamos, tipificamos. Esto es, definimos la realidad que nos construye en un momento dado. Mundo percibido que, Berger y Luckman (1972) consideran una construcción intersubjetiva, una realidad compartida, que se natu- 
raliza mediante procesos de interacción y comunicación que nos permiten compartir con los otros y experimentarlos.

De esta manera, aprehendemos a las personas, los sucesos, los acontecimientos y los objetos cotidianos mediante esquemas tipificadores como el lenguaje, que se vuelven progresivamente anónimos en la medida que se alejan de la interacción cara a cara. Es así como el conocimiento se construye no sólo con los próximos e iguales, sino también con los contemporáneos lejanos, y no sólo con ellos, sino con los antecesores de éstos, y con los sucesores que construirán, a la vez que yo, la historia global de la humanidad. El conocimiento fluye entre nosotros como una evidencia anónima, independiente de los hombres y mujeres que lo crearon y existe en tanto la expresividad humana logra concretarse u objetivarse en signos, símbolos o representaciones agrupados en sistemas accesibles. El sistema de signos por excelencia en la sociedad humana es el lenguaje, ya que posibilita la acumulación social y la transmisión global del conocimiento que orienta nuestra cotidianeidad.

El lenguaje nos permite, precisamente, ordenar el mundo otorgándole un significado común. Mediante la palabra organizamos nuestro pensamiento, le damos forma, definimos nuestras opciones de vida y nos expresamos. Sus posibilidades son infinitas, para "bien-decir" o "mal-decir", o, simplemente, para decir. Porque todo lo que existe y es, se puede decir, incluso el "yo" y el "otro". La palabra es pues un acto social porque desde que se dice, es para el otro. Los génesis son palabras que describen el mundo no sólo en el presente, sino en la permanencia.

La alteridad, entendida como la construcción de la identidad a través de los otros, es también palabra. La palabra incluye al otro, le da un lugar para invocar una respuesta, para definir un hecho, un gesto, una acción o un objeto. De hecho, "el lenguaje, en cuanto sistema simbólico, no se limita a reflejar el mundo: ningún sistema simbólico lo hace. Su relación es más compleja y dinámica, puesto que cualquier representación es también una recreación de lo representado" (De Bustos, 2000: 106). El lenguaje es creador, forja la comunidad, dice lo que es y lo que no es. Por ello, mediante la palabra, objetivamos la construcción social, de manera tal, que las personas percibimos el mundo como una realidad otorgada que existe fuera de nosotros, aunque en realidad es un producto humano, una arquitectura sensible con unas coordenadas específicas.

A nivel individual, la primera palabra, la creadora, es el nombre. Nuestra historia empieza ahí: te dicen, y ya eres para el otro. Así, en el nombre de cada quién, habita la génesis de la alteridad. De hecho, la existencia personal se concreta en un instante preciso: la imposición del nombre, antes de eso, no había nada. Nuestro nombre es la expresión inconsciente de los deseos, frustraciones, miedos, ambivalencias, esperanzas y sueños de aquel que nos ha nombrado "desde la perspectiva de la vida de alguien y dentro del contexto de las emociones de ese alguien" (McEwan y Egan, 1998: 10). Por eso, cada persona es un entramado infinito en el que se mezclan todas las variables, hasta el punto de que cualquier hipótesis podría ser cierta en nosotros. Tanto es así, que ni tan siquiera nuestro nombre es definitivo, de hecho, se adapta a la construcción que hacemos con los otros y sufre variaciones relacionadas con los procesos de socialización. De algún modo, cada vez que alguien nos dice, nos inventa, de la misma manera que, cada vez que nosotros decimos, creamos un "otro yo" diferente. Así, Mary Kramp (2004) señala que la investigación narrativa implica un estudio sistemático de la experiencia y de los significados personales, y de cómo se construyen estos acontecimientos por sujetos activos, especialmente en un tiempo y lugar, creando escenarios para el argumento narrativo. 


\section{La alteridad como encuentro: yo soy el otro.}

La alteridad es el lugar del otro en el yo, y, por tanto, implica el nosotros. Así, el yo siempre está referido al otro, en el deseo del encuentro que colabora en la construcción, siempre en tránsito, de saber quiénes somos "en relación a". La alteridad propone la diferencia entre el ser juntos y el estar juntos pues contribuye a la constitución de la subjetividad a través de la experiencia de ser en el otro. La educación para la vida, en cualquier contexto o ámbito educativo, debe atender el Saber Ser desde su complejidad, fragilidad, finitud y singularidad y reflejarla hacia el entorno, hacia el otro y hacia nosotros mismos (López F.-Cao, 2014).

Así, la alteridad se construye, en el día a día, desde la palabra del que la pronuncia al que la escucha y la convierte en significado compartido. En ese sentido, no solo sería una palabra, mirada, gesto o intención lo que nos construye, sino esa misma palabra, mirada, gesto o intención en el encuentro que nos permite saber que existimos ya que existe ese otro (Kapuscinski, 2012). La alteridad reside pues en la interpelación, la presencia y permanencia en el Ser en relación que se basa en lo diverso, singular y absolutamente propio a través de procesos de subjetivación que conforman ese "uno" y que no es en "sí mismo", sino en la relación de ese "sí mismo" con otro. Se trata, pues, de pensar y concebir también la educación como un encuentro de posibilidades y aperturas para la empatía y el compromiso.

Esta propuesta, sensible a la alteridad, propone fortalecer los vínculos construidos para contemplar el lugar de las emociones con otros. Es decir, reconocer los ámbitos para la vida en relación de los educandos, más allá de simples procesos socializadores, descentración evolutiva o autonomía personal que se preservan en estructuras curriculares muy apegadas a lo programado. En esta previsibilidad, el encuentro se considera casi como predeterminado y muchas veces son los espacios educativos quienes deciden quién es el otro. Es preciso, pues, repensar los lugares y los tiempos que se ofrecen en los contextos educativos para habilitar los procesos de subjetivación y valorar las aportaciones de cada biografía o historia de vida.

Estos espacios y lugares para la vida de relación son un guión siempre abierto a las diferentes voces que allí concurren en el día a día. Es decir, ponen el acento en las relaciones y en los encuentros, en el diálogo y la negociación, en la reflexión y el pensamiento. Procesos que implican la verdadera esencia del sentido del encuentro y el entendimiento con "otros" en un espacio afectivo o vaivén de intercambio de espacio y tiempo que es la vida como lugar donde se proyectan los yoes a través de sus propias historias, imaginarios y deseos para construir la realidad del "nosotros". Ese vaivén, es pues una experiencia siempre creadora en el espacio-tiempo y, además, una forma básica de vida en relación.

De esta manera, también la comunidad educativa puede convertirse en lugar de actuación y ámbito de creación para pensar, sentir y hacer desde cada historia, imaginario y deseo que construya el sentido de pertenencia, identidad y relación. Hablamos, pues, de sentidos de participación que se manifiestan a través de las propuestas del arte relacional para la sublimación de la vida cotidiana como manifestación creativa. En estas acciones se crea un verdadero contexto de inclusión, posibilitando un espacio de encuentro e intercambio que contribuye al crecimiento personal y colectivo. Ambos territorios se necesitan mutuamente al ser habitados desde las emociones y ser permeables a los acontecimientos y a la vida. 
Una manera de implicar a la comunidad educativa puede ser a través de proyectos o manifestaciones artísticas que permitan construir el aprendizaje comunitario sustentado en un relato colectivo basado en los acontecimientos, símbolos y procesos de vida que concurren como singular entramado de biografías. Desde esta propuesta relacional, la comunidad educativa se representa como lugar de narratividad pues cada persona realiza aportaciones que se consideran valiosas por ser únicas e irrepetibles. Cada gesto, imagen o significado, pueden ser el hilo invisible que sirva para tejer el sentido de la narración que se comparte en el espacio-metáfora como lugar simbólico para la celebración del ser juntos.

Así, los objetos, las imágenes y las palabras son la representación y la memoria de estos procesos como mediadores en la construcción compartida de significados y la creación de procesos de esperanza. Se constituye así el espacio potencial como lugar para la experiencia cultural que, para su emerger y existencia, depende del encuentro con el otro a través de mediadores en la comunicación como esos objetos, imágenes y palabras.

Es decir, metáforas transformadoras que implican a las personas participantes en estas acciones sobre el modo de entender y entenderse en el mundo. Metáforas que evocan las fronteras porosas o relacionales que nos convocan como humanidad y seres de relación.

\section{Propuesta de acción: arquitecturas del pensamiento.}

La propuesta de creación colectiva se plantea de manera interdisciplinar desde la convergencia de los recorridos vitales y profesionales de los autores: la educación, las artes y la sociología. Un planteamiento holístico que pretende no separar las disciplinas artísticas de la vida de relación, sino integrarlas. Así, el arte no es el resultado de hacer algo, sino que responde más bien a un sentir relacional. Por ello pensamos, a través de esta propuesta, que el arte posibilita el Ser en relación.

La idea de generar un encuentro en un mismo espacio compartido propició un clima de bienestar entre los alumnos y profesores que participaron en la experiencia que se muestra a continuación a través de narrativas visuales. Así, cada voz e historia de vida resultó una aportación imprescindible que nutrió al gran grupo y posibilitó una dinámica de creatividad donde surgió lo extraordinario y lo inesperado. Así, la interacción social permite la convergencia y forma parte de la esencia del proyecto: crear juntos "arquitecturas" para Ser y sentir con otros, nombrar, reconocer, crear, aprender o desaprender, etc.

En este sentido, esta propuesta de creación colectiva pretendió resignificar un espacio con la aportación de todos y cada uno de los participantes pues los lugares investidos y las arquitecturas humanas que allí se crean colectivamente, representan la comunidad. Entendemos que la escuela, como metáfora de la vida, no debe compartimentar o separar en el aula lo que de por si está unido. Atendiendo a esta idea, se pretendió construir una metáfora que cuestionara una realidad en la que todo lo que no puede transformarse y adaptarse, deje de tener sentido, ya que, tal y como señala De Bustos (2000: 108) "La metáfora no pone en cuestión la estructura del mundo, sino la de nuestra relación con él. Nos impide asentarnos en una visión fija de la realidad, cuya pretensión de legitimidad es esa propia fijeza." 
Es decir, el proyecto precisó de un lugar distinto al aula y que diera acogida a un relato colectivo que iría construyéndose a partir de las biografías de los participantes, generando progresivamente una "arquitectura humana" para habitar las emociones y la memoria. Esta arquitectura colaborativa tomó forma a través de la palabra escrita como "materia prima", pues la escuela precisa de lugares, no sólo físicos y tangibles, sino también resignificados para reconocer las relaciones, los pensamientos y los afectos. En definitiva, las formas culturales, entendidas como una construcción social que sólo tiene sentido en la alteridad. Es decir: si representa el nosotros.

Así pues, consideramos como importante la alteridad, definida como la construcción mutua de la identidad a través de la metáfora-puente que permite llegar "al otro" y representar recíprocamente un concepto de por sí abstracto, pero que, cuando se concreta en nosotros mismos a través de la expresión de los diferentes lenguajes, se vuelve poliédrico. Precisamente, atendiendo a esta diversidad de representación, son necesarias las metáforas para construir una realidad significativa, que exprese el concepto y lo fije en la emoción colectiva.

De esta manera, compartimos diferentes reflexiones previas a la realización de la acción como entender el arte desde una perspectiva holística, relacionar la escuela con la vida a través de la expresión de las emociones, favorecer la relación de los espacios con los lugares interpersonales, establecer interacciones posibles que conecten el aula con la realidad y que puedan representarse desde una perspectiva sensible e integrada.

Para concretar la propuesta de acción, se tomó como referente la obra de la artista Chiharu Shiota "The Key in the Hand", Bienal de Venecia (2015). Esta artista japonesa trabaja con objetos simbólicos, realizando instalaciones que tratan la vinculación a la memoria. Como en el entramado de vida, los objetos suspendidos como recuerdos o momentos que flotan como "arquitecturas del pensamiento". Así, la justificación en la elección de la obra de esta artista está basada en la creación de ambientes impregnados de una fuerte carga emocional para evocar temas como la ausencia y la presencia, el vínculo y desapego, el yo y el otro en relación con el entorno próximo y el uso de objetos simbólicos para representar la construcción de la alteridad. Shiota realiza instalaciones o espacios simbólicos que acumulan las experiencias vividas por otras personas colaboradoras en sus proyectos a través de palabras de agradecimiento u objetos personales como llaves que simbolizan la identidad, disponiendo este material en entramados realizados con "el hilo rojo de la vida". Su trabajo resultó ser una interesante metáfora para dar forma a la creación del relato de la acción performativa que permitió visibilizar las relaciones del grupo entre iguales y profesores participantes.

\section{Simbología de los lugares y los objetos para la acción.}

Para ofrecer una "escenografía de la posibilidad", los lugares, hechos y objetos simbólicos que se eligieron para la acción performativa dialogaban entre sí y contenían una historia común en el marco único de la propuesta. Estos fueron:

- La silla representa la presencia del yo, el lugar de partida y llegada.

- El nombre es el punto de partida, el inicio. Desde que nos nombran, existimos para los otros y nos proyectamos hacia ellos. 
- La llave representa la posibilidad. Abre o cierra, y va unida al yo y al otro.

- El hilo es el camino del encuentro y del desencuentro. Caminar es inevitable.

- El color rojo representa el destino y la pulsión de la vida de relación con otros. Según una antigua leyenda japonesa, de nuestro dedo meñique nace un hilo rojo que nos conecta a todas aquellas personas que estamos destinados a conocer. El hilo puede tensarse o enredarse, pero nunca romperse.

- Las tarjetas escritas con palabras simbolizan diferentes instantes significativos de la vida que nos construyen. Son las palabras que dicen que y quienes somos. Así, una tarjeta apalabrada como seña de identidad individual y colectiva es una manera de reconocer la diversidad y lo extraordinario de cada persona que actúa en el mundo.

- Las pinzas "atan" y unen a la vida que fluye a través de los hilos hasta formar una red de instantes-palabra.

- La red es la metáfora de la posibilidad, pues nombrar el mundo (y a nosotros mismos, como parte inherente de él), es tejer un tapiz de significados que, llegando del pasado, nos incluye en un relato que nos vincula en el presente $\mathrm{y}$ nos permite trascender pues fuimos, somos y seremos palabra en el puente tendido entre el yo y el nosotros.

- La elección de la playa como lugar de la intervención se realizó atendiendo a un criterio simbólico como espacio visible que reproduce la estructura de la "educación tradicional", en cuanto a los roles y la distribución de los estatus de poder asociados a los mismos. Sin embargo, en un "lugar" desposeído de aula donde es posible construir relaciones y conexiones emocionales diferentes ya que invita a comportarse de otro modo. En este sentido, al resignificar el espacio simbólico de la playa mediante la construcción colectiva, al decirlo, y al poseerlo, lo hacemos aula nuestra.

- El mar, referente simbólico como destino final. Al sumergir los objetos que representan a las personas, simbolizamos el encuentro pleno que significa fundirse con el todo.

\section{Breve relato de la acción performativa.}

Una vez construida la metáfora colectiva en el aula y desde la necesidad e interés de los alumnos por narrarse a otros como dinámica de integración, se solicitó a los participantes que contasen su historia en palabras significativas, partiendo de su propio nombre. Después, cada persona se encaminó en silencio a la playa (cercana al centro educativo donde se realizó la experiencia en la ciudad de A Coruña), portando su propia silla o "yo simbólico". Se proponía así el recorrido de un camino que partiese del aula de referencia y llegase de nuevo a ella, cargado ahora de palabras entregadas y recibidas. Una vez allí, las sillas se sumergieron en la orilla del mar, para representar la vuelta a un origen común y se extendieron después en la arena formando un círculo o comunidad simbólica.

A partir de las posibilidades de los objetos simbólicos elegidos para la experiencia, los participantes emplearon hilos para trenzarse con los otros hasta formar una red tupida que dibujase el "aire" o espacio de relación que mediaba entre unos y otros. Sobre esta malla, se depositaron las tarjetas escritas con las palabras signifi- 
cativas, atadas con pinzas y siguiendo el recorrido del hilo que se extendía hasta el "lugar" de otro participante en el círculo de sillas, de modo que el propio nombre quedaba enlazado con el de otra persona y poco a poco, con todo el colectivo. En esta red tejida para visibilizar la comunidad, también se incluyeron las llaves que cada participante había aportado como símbolo del permiso otorgado y como expresión de apertura hacia los demás. Cada llave estaba unida con un hilo rojo para representar la trama de la vida y todas las conexiones posibles.

Para finalizar, las personas intercambiaron palabras adjetivadoras, escritas en etiquetas adhesivas que permanecieron en la piel o el vestido de los otros para decirse mutuamente y proponer la palabra escrita como intercambio de deseos y esperanzas.

Tras terminar la construcción simbólica de la comunidad, se recogieron las tarjetas que contenía la red, y tras su lectura, se comprobó que la mayoría de las palabras escritas y compartidas nos decían a todos porque lo humano es reflejo del otro en nuestra mismidad y al mismo tiempo, otredad. Es decir, en la palabra habita nuestra biografía, explicada y nombrada en toda su singularidad y pluralidad.

\section{Conclusiones}

Esta propuesta interdisciplinar considera pues el contexto educativo como "arquitectura" para contener y ofrecer un marco simbólico para el encuentro que permitió, a través de la experiencia descrita, construir identidades relacionales desde la mediación simbólica de los objetos, las acciones y la palabra escrita compartida.

Así, la propuesta relacional de la performance en contextos escolares y académicos se presenta como lugar para la producción de intersubjetividad en relación con otros. La acción performativa construye los significados y las formas de encuentro que colaboran en la elaboración compartida de sentido a través de una acción simbólica. De esta manera, la comunidad se representa en un relato colectivo entendido como singular escenario de posibilidad para la construcción del nosotros.

La performance se nutre con las diferentes experiencias, visiones y maneras de entendimiento mutuo que permiten a los participantes ser capaces de reconocer, gestionar y desarrollar sus propias expectativas, decisiones y compromisos para tomar conciencia de quienes son en relación con otros para la mejora sensible del ambiente de convivencia, la integración y la calidad de las relaciones humanas que se promueven, reconocen y celebran a través de las acciones artísticas comunitarias.

Por todo ello, cada historia de vida resulta una aportación imprescindible para la construcción de la "arquitectura humana" que permite habitar la metáfora compartida del nosotros en el aquí y el ahora que a continuación se relata en imágenes. 
9. Narrativas visuales de la acción performativa:
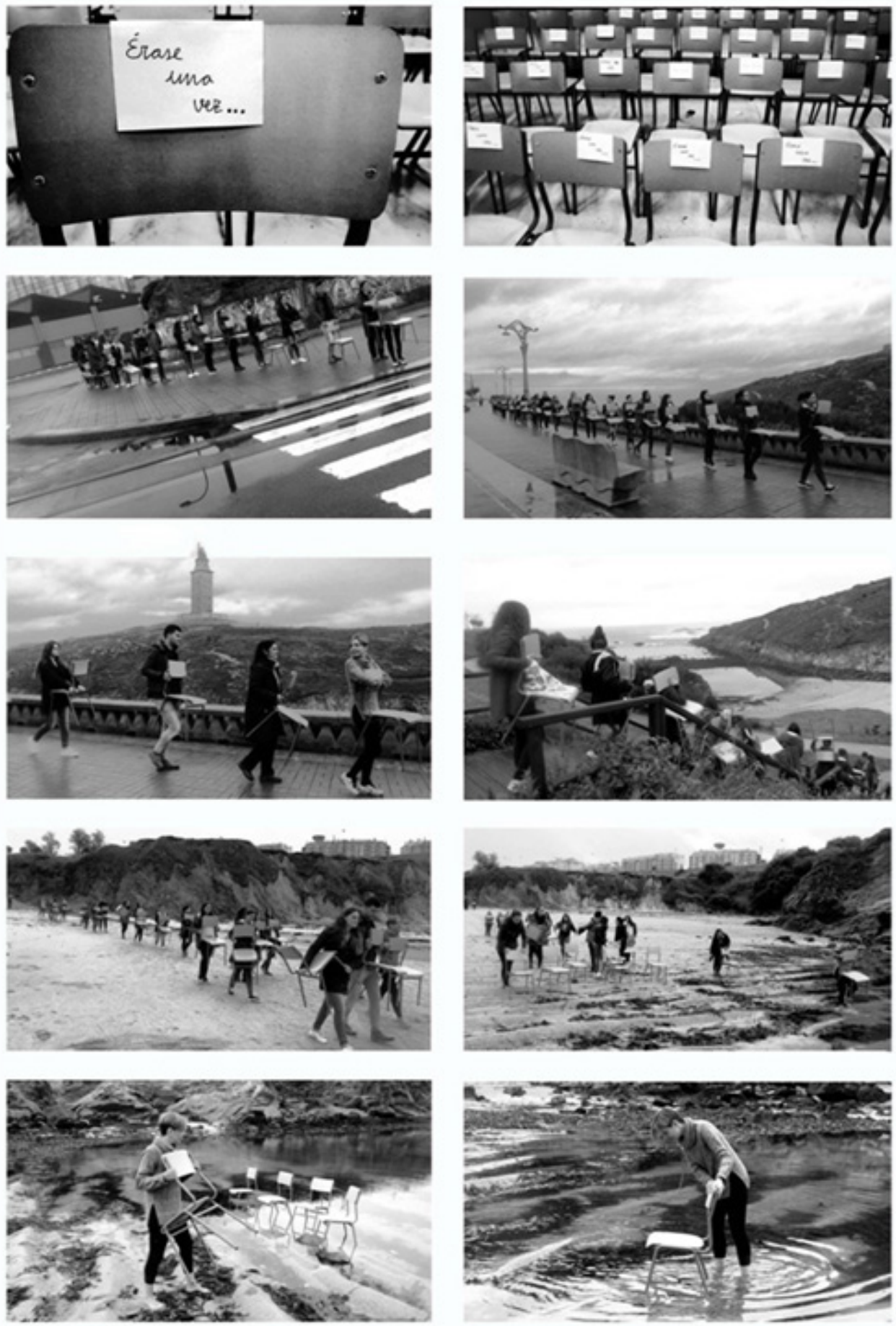

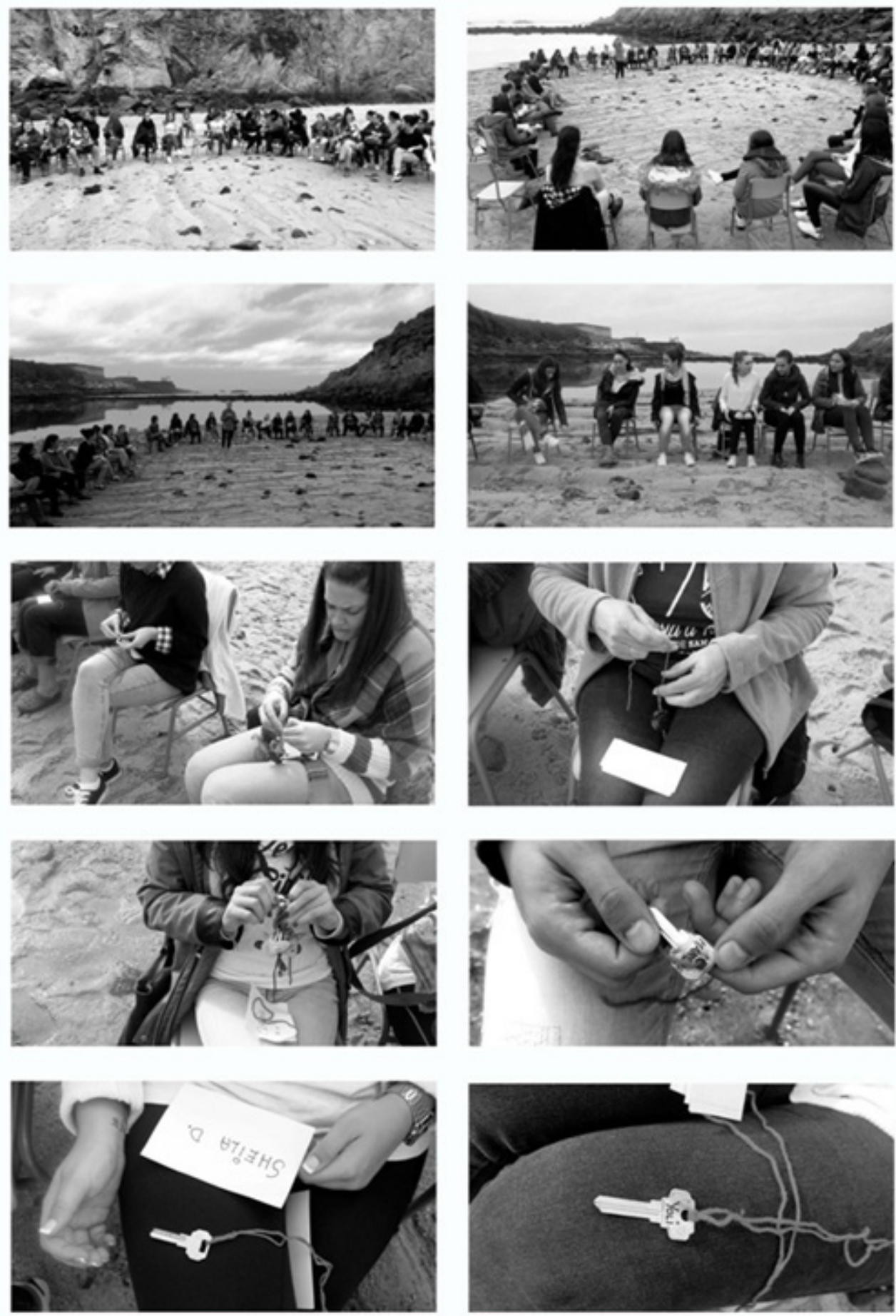

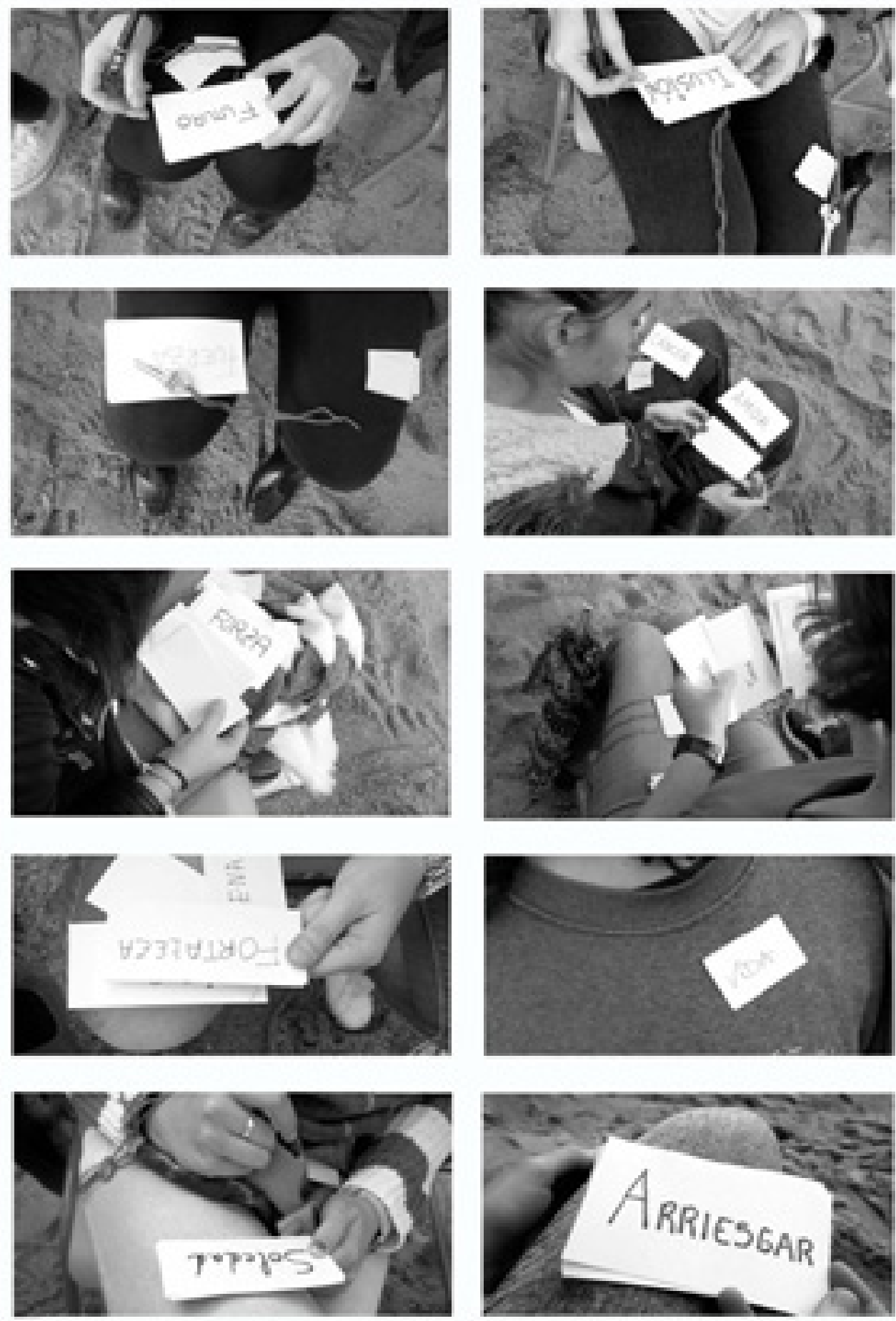

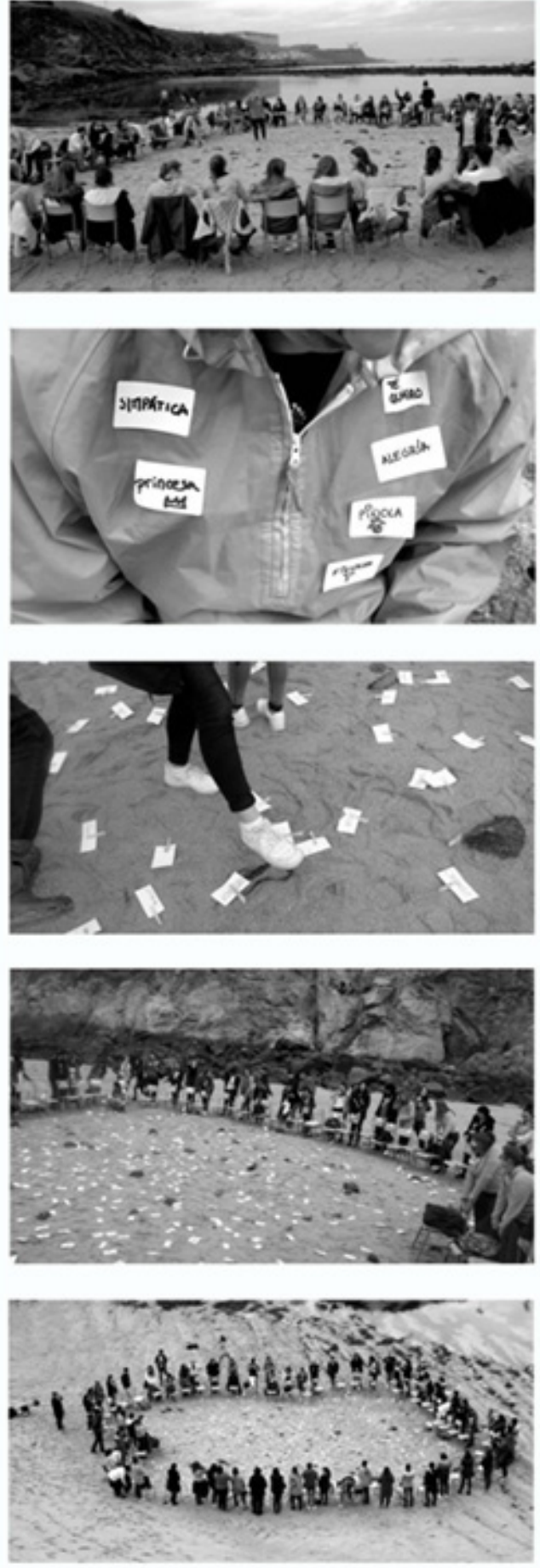
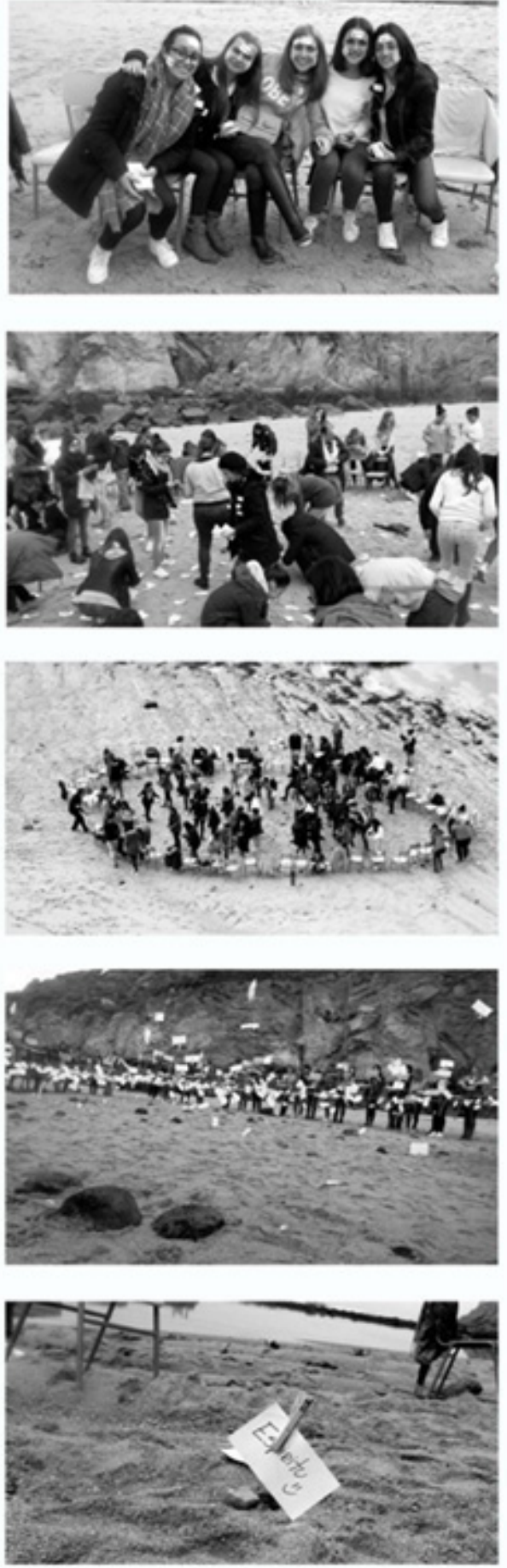


\section{Referencias bibliográficas:}

Augé, M. (2000). Los no lugares. Espacios del Anonimato. Barcelona, Gedisa.

Berger, P.l. y Luckman, T. (1972). La construcción social de la realidad. Buenos Aíres, Amorrurtu.

Bourdieu, P. (2012). La distinción. Madrid, Santillana.

De Bustos, E. (2000). La Metáfora. Ensayos interdisciplinares. Madrid: S.L. Fondo de Cultura Económica de España. Universidad Nacional de Educación a Distancia.

Elías, N. (1990a). Compromiso y distanciamiento. Barcelona, Ediciones 62.

Elías, N. (1990b). La sociedad de los individuos. Barcelona, Península.

Kapuscinski, R. (2012). Encuentro con el otro. Barcelona, Anagrama.

Kramp, M. (2004). Exploring life and experience through narrative inquire. Mahwah N.J: Eribaum.

Lévinas, E. (1993). El tiempo y el otro. Barcelona: Paidós Ibérica.

Lévinas, E. (1999). De otro modo que ser, o más allá de la esencia. Salamanca, Sígueme.

Lólpez-Cao, F., M. (2014). Memoria, ausencia e identidad. Madrid, Eneida.

Mc Ewan y Egan (1998). Compilación. La narrativa en la enseñanza, el aprendizaje y la investigación. Buenos Aires, Amorrortu.

Shiota, C. (2015). The Key in the Hand (Bienal de Venecia). Recuperado de: http://2015. veneziabiennale-japanpavilion.jp/en/ Consultada el 20 de octubre a las 14:00. 